\title{
Analisis Gaya Bahasa dan Nilai Pendidikan dalam Novel Pulang Karya Tere Liye
}

\author{
Windi Rahmayanti ${ }^{1)}$ \\ Universitas Indraprasta PGRI \\ Jalan Nangka No. 58 C/TB. Simatupang, Tanjung Barat, Jakarta Selatan 12530
}

\author{
E. Zaenal Arifin ${ }^{2}$ \\ Universitas Indraprasta PGRI \\ Jalan Nangka No. 58 C/TB. Simatupang, Tanjung Barat, Jakarta Selatan 12530 \\ rahmawindi25@gmail.com ${ }^{1)}$
}

\begin{abstract}
The purpose of this study was to analyze the use of language styles in the novel Pulang by Tere Liye and analyze the value of Education contained in the novel Pulang by Tere Liye. By understanding the language style and values of education, readers get two benefits, namely an understanding of language style and knowledge about the value of religious, moral and social education. The language style that the researcher will analyze only includes the style of personification, metaphor and hyperbole. The research method used by researchers in analyzing this novel is a qualitative method with analytic descriptive techniques, which describe and analyze words that contain the style of personification language, metaphors and hyperbole, and the educational values contained in the novel. The steps in analyzing the data are 1) reading the whole novel in order to get a picture of its contents; 2) analyzing sentences containing personification, metaphor and hyperbole which are contained in the novel Pulang by Tere Liye; 3) analyzing sentences containing Educational values contained in the novel Pulang by Tere Liye. After the writer analyzes the novel, it can be concluded that from the personification, metaphor and hyperbole language style, the writer is more dominant using the personification language style amounting to $39.62 \%$, then the metaphorical style style amounting to $33.96 \%$ and hyperbole language style amounting to $26.42 \%$. less author use. Pulang also contains religious education values totaling $18.75 \%$, moral values totaling $50 \%$ and social values totaling $31.25 \%$.
\end{abstract}

Keywords: Language style analysis, Educational Values

\begin{abstract}
Abstrak
Tujuan penelitian ini untuk menganalisis penggunaan gaya Bahasa dalam novel Pulang karya Tere Liye dan menganalisis nilai Pendidikan yang terdapat dalam novel Pulang karya Tere Liye. Dengan memahami gaya Bahasa dan nilai-nilai Pendidikan, pembaca memperoleh dua manfaat yaitu pemahaman tentang gaya Bahasa dan pengetahuan tentang nilai Pendidikan religi, moral dan sosial. Gaya Bahasa yang akan dianalisis peneliti hanya meliputi gaya Bahasa personifikasi, metafora dan hiperbola. Metode penelitian yang digunakan peneliti dalam menganalisis novel ini adalah metode kualitatif dengan Teknik deskriptif analitik, yaitu menguraikan sekaligus menganalisis kata-kata yang mengandung gaya Bahasa personifikasi, metafora dah hiperbola, serta nilai pedidikan yang terkandung dalam novel tersebut. Adapun langkah-langkah dalam menganalisis data adalah 1) membaca keseluruhan novel agar memperoleh gambaran tentang isinya; 2) menganalisis kalimat yang mengandung gaya bahasa personifikasi, metafora dan hiperbola yang terkandung dalam novel Pulang karya Tere Liye; 3) menganalisis kalimat yang mengandung nilai-nilai Pendidikan yang terkandung dalam novel Pulang karya Tere Liye. Setelah penulis menganalisis novel maka dapat disimpulkan bahwa dari gaya bahasa personifikasi, metafora dan hiperbola, penulis lebih dominan
\end{abstract}

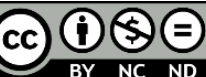

Creative Commons Attribution-NonCommercial-NoDerivatives 4.0 International License 
menggunakan gaya Bahasa personifikasi berjumlah 39,62\%, kemudian gaya bahasa metafora berjumlah $33.96 \%$ dan gaya bahasa hiperbola berjumlah $26,42 \%$. lebih sedikit digunakan pengarang. Novel Pulang juga mengandung nilai Pendidikan religi berjumlah 18,75\%, nilai moral berjumlah $50 \%$ dan nilai sosial berjumlah $31,25 \%$.

Kata Kunci: Analisis gaya bahasa, Nilai Pendidikan

\section{PENDAHULUAN}

Sastra merupakan wujud gagasan seseorang melalui pandangan terhadap lingkungan sosial yang berada di sekelilingnya dengan menggunakan bahasa yang indah. Sastra hadir sebagai hasil perenungan pengarang terhadap fenomena yang ada. Sastra sebagai karya fiksi memiliki pemahaman yang lebih mendalam, bukan hanya sekadar cerita khayal atau angan dari pengarang saja, melainkan wujud dari kreativitas pengarang dalam menggali dan mengolah gagasan yang ada dalam pikirannya.

Endraswara (2003:7) menyatakan bahwa karya sastra merupakan fenomena unik yang di dalamnya memiliki serangkaian makna dan fungsi. Makna dan fungsi ini sering kabur dan tak jelas. Oleh karena itu, karya sastra sarat dengan imajinatif. Itulah sebabnya, peneliti sastra memiliki tugas untuk mengungkapakan elemenelemen dasar pembentuk sastra dan menafsirkan sesuai paradigma atau teori yang digunakan. Karya sastra pada dasarnya merupakan ungkapan pengalaman pengarang dalam menghayati berbagai bentuk masalah kehidupan. Pengalaman itu lantas dituang ke dalam sebuah tulisan (karya sastra) dan dengan gaya imajinasinya yang selalu terpengaruh oleh apa saja yang pernah dilintasi, termasuk juga bacaanbacaan yang pernah dibaca. Adapun pengarang hidup dalam alam budaya tertentu sehingga pandangan-pandangannya terhadap masalah-masalah kehidupan pun dalam banyak hal akan tercermin dalam karya-karyanya.

Budianta (2008:19) menyatakan bahwa karya sastra menjadi sarana untuk menyampaikan pesan tentang kebenaran, tentang apa yang baik atau yang buruk. Ada pesan yang sangat jelas disampaikan, ada juga pesan yang disampaikan secara tersirat. Karya sastra juga dapat dipakai untuk menggambarkan apa yang ditangkap pengarang tentang kehidupan sekitarnya. Gagasan-gagasan yang muncul ketika menggambarkan karya sastra dapat membentuk orang tentang kehidupan itu sendiri.

Nurgiyantoro (2002: 22) menyatakan sebuah novel merupakan totalitas, novel mempunyai bagian-bagian, unsur-unsur yang saling berkaitan satu dengan yang lain secara erat dan saling menguntungkan. Novel sebagai salah satu bentuk karya sastra menampilkan suatu keadaan masyarakat tertentu yang merupakan gambaran kehidupan. Salah satu bentuk karya sastra yang banyak diminati oleh pembaca adalah novel. Dalam hal ini penulis ingin mengambil salah satu jenis karya sastra yaitu novel Pulang karya Tere liye. Dapat dilihat dari perkembangan novel di Indonesia sekarang ini cukup pesat, terbukti dengan banyaknya novel-novel lama dan baru yang telah diterbitkan, salah satunya novel Pulang karya Tere liye yang dipergunakan oleh penulis sebagai objek penelitian. Dari begitu banyak novel yang diterbitkan, peneliti hanya tertarik dengan novel Pulang karya Tere liye ini karena dilihat dari judulnya saja sudah dapat ditebak bahwa didalam novel ini banyak teka- 
teki kehidupan yang pantas untuk diteliti. Teka-teki kehidupan dalam novel tercermin dari gaya bahasa. Gaya bahasa adalah tingkah laku pengarang dalam menggunakan bahasa.

Berdasarkan yang diungkapkan Nurgiyantoro (2002: 272) bahasa dalam seni sastra ini dapat disamakan dengan cat warna. Keduanya merupakan unsur bahan, alat, dan sarana yang mengandung nilai lebih untuk dijadikan sebuah karya. Sebagai salah satu unsur terpenting tersebut, maka bahasa berperan sebagai sarana pengungkapan dan penyampaian pesan dalam sastra.

Gaya bahasa dalam penulisan merupakan salah satu unsur yang menarik dalam sebuah bacaan. Setiap penulis mempunyai gaya yang berbeda-beda dalam menuangkan setiap ide tulisannya. Setiap tulisan yang dihasilkan nantinya mempunyai gaya penulisan yang dipengaruhi oleh penulisnya, sehingga dapat dikatakan bahwa, watak seorang penulis sangat memengaruhi sebuah karya yang ditulisnya.

Menurut Keraf (2010: 112) menyatakan bahwa gaya atau khususnya gaya bahasa dikenal dalam retorika dengan istilah style. Kata style diturunkan dari kata Latin stilus, yaitu semacam alat untuk menulis pada lempengan lilin. Kelak pada waktu penekanan dititik beratkan pada keahlian untuk menulis indah, maka style lalu berubah menjadi kemampuan dan keahlian untuk menulis atau mempergunakan kata-kata secara indah.

Dari pernyataan di atas, maka dalam buku sastra atau bacaan yang mengandung nilai estetik dapat membuat para pembaca lebih bersemangat dan tertarik untuk membacanya. Gaya bahasa atau style menjadi masalah atau bagian dari diksi atau pilihan kata yang mempersoalkan cocok tidaknya pemakaian kata, frasa atau klausa tertentu untuk menghadapi situasi tertentu. Jadi, jangkauan gaya bahasa sebenarnya sangat luas, tidak hanya mencakup unsur-unsur kalimat yang mengandung corak-corak tertentu.

Setiap pengarang mempunyai gaya bahasa yang berbeda-beda dalam mengkomunikasikan gagasannya. Ada yang menggunakan bahasa yang sedikit mengajak pembaca bermain dengan kata-kata, artinya pembaca diajak untuk sedikit berpikir agar mampu memahami maksud dari setiap bahasanya. Ciri khas pengarang dalam menggunakan bahasa tersebut sesungguhnya mempunyai nilai lebih tersendiri, yang semua itu bergantung dengan selera pembaca.

Pembaca yang baik adalah pembaca yang mampu memahami isi cerita dan mampu menceritakannya kembali kepada orang lain tentang apa yang dibacanya Sebenanya yang mampu memahami isi cerita sebuah karya sastra secara lengkap, dan tepat adalah tercipta berdasarkan pengamatan pengarang atas lingkungannya serta pengalaman batinnya sendiri. Jadi, maksud dari cerita yang tepat hanya pengarang sendirilah utuh pengarang itu sendiri.

Pada dasarnya, karya sastra mempunyai tujuan untuk menyampaikan pesan moral dan nilai pendidikan yang baik. Pesan moral dan nilai-nilai lain yang terkandung dalam karya sastra diharapkan dapat diaplikasikan dalam kehidupan sehari-hari. Masyarakat pembaca biasanya lebih mudah untuk dinasihati melalui karya sastra daripada secara langsung. Itulah salah satu keunggulan karya sastra. yaitu mengandung pesan moral yang luas sesuai dengan kebutuhan pembaca tanpa terlihat menggurui.

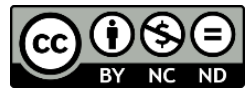

Creative Commons Attribution-NonCommercial-NoDerivatives 4.0 International License 
Tere Liye mempunyai gaya bahasa yang khas dalam menuturkan ceritanya. Kalimat-kalimatnya banyak yang memanfaatkan gaya bahasa, seperti metafora, hiperbola, personifikasi, simile, paradoks, dan lain-lain. Perpaduan beberapa gaya bahasa dalam satu karya sastra menyebabkan banyak pembaca tidak mampu memahami maknanya.

Hal ini mengacu pada pendapat Rahmanto (1998:16), bahwa pengajaran sastra dikatakan dapat bermanfaat apabila mencakup empat hal, yaitu membantu keterampilan berbahasa. meningkatkan pengetahuan budaya, mengembangkan cipta dan rasa, juga menunjang pengembangan watak. Keindahan sebuah karya sastra tidak terlepas dari keindahan bahasa yang digunakan pengarang.

Gaya bahasa yang terdapat dalam novel Pulang memberikan kesan hidup, memperindah, dan mengefektifkan pengungkapan gagasan pengarang. Novel Pulang ini memanfaatkan berbagai jenis gaya bahasa untuk mengungkapkan setiap ceritanya. Akan tetapi, gaya bahasa yang akan dianalisis dalam penelitian ini hanya difokuskan pada gaya bahasa personifikasi, metafora, dan hiperbola karena gaya bahasa tersebutlah yang paling dominan digunakan.

Berdasarkan latar belakang di atas, penulis tertarik untuk membahas tentang gaya bahasa dan nilai pendidikan yang terdapat dalam sebuah karya sastra. Untuk itu, penulis akan mengkaji penelitian yang berjudul Analisis Gaya Bahasa dan Nilai Pendidikan dalam Novel Pulang Karya Tere Liye.

Berdasarkan batasan masalah di atas, penulis merumuskan masalah sebagai berikut: Bagaimana penggunaan gaya bahasa personifikasi, metafora dan hiperbola yang terdapat dalam novel Pulang karya Tere Liye? Dan Nilai pendidikan apa sajakah yang terdapat dalam novel Pulang karya Tere Liye?

\section{METODE}

Metode yang digunakan dalam penelitian ini adalah metode kualitatif Sugiono (2011: 15) menyatakan bahwa metode penetitian kualitatif adalah metode penelitian yang berlandaskan pada filsafat pospositivisme digunakan untuk meneliti pada kondisi objek yang alamiah, (sebagai lawannya eksperimen) di mana peneliti sebagai instrument kunci, pengambilan sampel sumber data dilakukan secara purposive, dan snowbaal, teknik pengumpulan data dengan triangulasi (gabungan), analisis data bersifat induktif/ kualitatif, dan hasil penelitian kualitatif lebih menekankan makna daripada generalisasi.

Metode penelitian kualitatif tepat digunakan untuk menganalisis objek sastra berupa teks dengan tujuan akhirnya makna, berbagai gejala tersembunyi di balik deskriptif analitik. Metode deskriptif analitik adalah metode dengan cara menguraikan sekaligus menganalisis. Setiap data dianalisis secara langsung tanpa menunggu deskripsi secara menyeluruh.

Metode deskriptif lebih banyak berkaitan dengan kata-kata. Karya sastra sebagai data primer dideskripsikan ke dalam kata-kata dan kalimat. Tujuan umum penelitian ini adalah menganalisis penggunaan gaya bahasa personifikasi, metafora dan hiperbola dan nilai-nilai pendidikan agama, moral dan sosial dalam novel Pulang karya Tere Liye. 
berikut:

Analisis data dalam penelitian ini akan dilakukan dengan langkah - langkah

1. Membaca berulang-ulang secara keseluruhan novel Pulang agar memperoleh gambaran menyeluruh tentang isinya.

2. Mengklasifikasikan kalimat berdasarkan majas personifikasi, metafora, dan hiperbola.

3. Menganalisis makna kalimat bergaya bahasa personifikasi, metafora dan hiperbola yang terdapat dalam novel Pulang dan menemukan makna tersirat dalam kalimat kalimat bergaya bahasa personifikasi, metafora, dan hiperbola.

4. Mengklasifikasikan nilai-nilai pendidikan agama, moral, dan sosial berdasarkan adegan cerita.

5. Menganalisis nilai-nilai pendidikan dalam novel Pulang terkait dengan makna tersiral yang terdapat dałam novel tersebut.

\section{HASIL DAN PEMBAHASAN}

\section{Hasil}

Peneliti akan menjelaskan tentang deskripsi data berupa kalimat yang mencerminkan gaya Bahasa personifikasi, metafora dan hiperbola. Selain itu, akan dijelaskan juga tentang kalimat yang mengandung nilai-nilai Pendidikan agama, sosial dan moral. Hal itu dikarenakan dalam penelitian ini hanya akan membahas tentang analisis gaya bahasa personifikasi, metafora, hiperbola dan nilai Pendidikan agama, sosial dan moral yang terdapat dalam novel Pulang karya Tere Liye.

Tabel 1. Tabel Rekapitulasi Temuan Penelitian

\begin{tabular}{ccccc}
\hline \multirow{2}{*}{ Gaya Bahasa } & Personifikasi & Metafora & Hiperbola & Jumlah \\
\cline { 3 - 5 } & 21 & 18 & 14 & 53 \\
\cline { 3 - 5 } Persentase & $39,62 \%$ & $33,96 \%$ & $26,42 \%$ & $100 \%$ \\
\hline Nilai & Religius & Moral & Sosial & Jumlah \\
\cline { 1 - 5 } Pendidikan & 6 & 16 & 10 & 32 \\
\cline { 1 - 3 } Persentase & $18,75 \%$ & $50 \%$ & $31,25 \%$ & $100 \%$ \\
\hline
\end{tabular}

\section{Pembahasan}

Berdasarkan deskripsi data temuan penelitian tersebut, berikut akan dianalisis nilai pendidikan serta gaya bahasa personifikasi, metafora, dan hiperbola yang terdapat dalam novel Pulang karya Tere Liye.

1. Nilai Pendidikan Religius

a. "Aku mengangguk. Mamakku juga mengajarkan berhitung di kampung. Pun diam-diam mengajariku mengenai, shalat, dan ilmu agama."(Liye, 2015: 48) 
Makna yang terdapat dalam kalimat tersebut adalah seorang ibu selalu mengajarkan anak-anaknya dengan hal yang baik tidak hanya pengetahuan yang ia ajarkan tapi ilmu agama yang menjadi dasar agar kehidupan anaknya kelak lebih baik.

b. "Adzan subuh terdengar dari masjid dekat markas keluarga Tong, suaranya sayup-sayup tiba dikamarku. Aku tergugu, ingat dulu Mamak sering mengajariku mengaji, juga mengajariku mengumandangkan adzan" (Liye, 2015: 193)

Makna kalimat tersebuat ialah suara adzan subuh mengingatkan tokoh bujang atas apa yang telah ibunya ajarkan. Suara adzan menandakan sudah waktunya kita meninggalkan segala aktifitas yang sedang dikerjakan dan menjalankan perintah-Nya untuk beribadah.

2. Nilai Pendidikan moral

a. "Mamak tau kau akan jadi apa di Kota sana... Mamak tahu... Tapi, tapi apa pun yang akan kau lakukan di sana, berjanjilah Bujang, kau tidak akan makan daging babi atau daging anjing. Kau akan menjaga perutmu dari makanan haram dan kotor. Kau juga tidak akan menyentuh tuak dan segala minuman haram." (Liye, 2015: 24)

Dari kutipan di atas membuktikan terdapat sikap tawakal yang dilakukan oleh para tokoh dalam novel Pulang karya Tere Liye. Sikap tawakal merupakan salah satu bentuk hubungan antara manusia dengan Tuhannya yang dilakukan oleh para tokoh dalam novel ini.

b. "Aku ikut tertawa, mengeleng tegas, lalu memasukkannya kembali ke dalam koper. Menurut hitunganku sudah enam kali White menyelesaikan misi bersamaku, tapi tidak sekalipun dia bersedia menerima bayaraan. Dia selalu menganggap itu bagian dari utang budi karena aku pernah membebaskannya dari Baghdad. Aku akan mencatat semua batang emas milik White. Besok lusa, itu tetap menjadi haknya." (Liye, 2015: 162)

Dari kutipan di atas membuktikan terdapat hubungan antara manusia dengan manusia yang lainnya dalam novel Pulang karya Tere Liye. Contohnya adalah adanya sifat dermawan yang dicontohkan oleh para tokoh merupakan sikap moral yang sangat terpuji yang dapat kita contoh dalam kehidupan sehari-hari.

3. Nilai Pendidikan Sosial

a. "Sekian puluh ribu panggilan itu, kali ini aku baru memahaminya. Aku menyeka wajah yang basah oleh butiran air. Terlambat? Tidak juga. panggilan itu tidak pernah mengenal kata terlambat, panggilan itu selalu bekerja secara misterius.” (Liye, 2015: 398)

"Mamak, Bujang pulang hari ini. Tidak hanya pulang bersimpuh dipusaramu, tapi juga telah pulang kepada panggilan Tuhan. Sungguh, sejauh apapun kehidupan menyesatkan, segelap apapun hitamnya jalan 
yang kutempuh, Tuhan selelu memanggil kami untuk pulang. Anakmu telah pulang." (Liye, 2015: 400)

Dari kutipan di atas terlihat bahwa Bujang memiliki keyakinan bahwa sejauh apapun perjalanan manusia pasti kembali kepada Tuhannya. Bujang akhirnya menyadari bahwa begitu panjang perjalanan yang telah ia lampaui dan kini saaatnya ia kembali kepada panggilan Tuhan

b. "Berjanjilah kau akan menjaga perutmu (dari makanan dan minuman haram dan kotor) itu, Bujang. Agar.... Agar besok lusa, jika hitam seluruh hidupmu, hitam seluruh hatimu, kau tetap punya satu titik yang putih, dan semoga itu berguna. Memanggilmu pulang." (Liye, 2015: 24)

Dari kutipan di atas membuktikan bahwa Bujang telah melewati pertarungan demi pertarungan yakni melawan diri dari hawa nafsu dan godaan-godaan untuk bertindak yang tidak baik. Bujang akhirnya mampu melewati hal itu, karena Bujang selalu mengingat pesan yang disampaikan oleh ibunya.

4. Gaya Bahasa Personifikasi

Gaya bahasa personifikasi adalah gaya bahasa kiasan yang menggambarkan benda-benda mati atau sesuatu yang tidak bernyawa memiliki sifat kemanusiaan.

a. "Malam itu, di tengah hujan lebat, didasar rimba Sumatra yang berselimut lumut nan gelap,"

b. "Sesosok monster mengerikan telah mengambil rasa takutku."

Pada kutipan (a), kata berselimut lumut nan gelap seolah rimba Sumatra adalah manusia. Pada kutipan (b), kata mengambil rasa takutku seolah memiliki sifat insani yaitu membuat seseorang menjadi cemas dan takut.

c. "Hutan lebat mengadang diatasnya, berselimut kabut."

d. "Tadi malam kami hamper tersesat, satu mobilku juga hamper terguling ditelan lembah gelap.”

Pada kutipan (c), kata berselimut kabut seolah hutan adalah manusia. Pada kutipan (d), kata ditelan lembah gelap yang berarti mobil terguling di lembah Sumatra yang tidak ada cahaya atau gelap.

5. Gaya Bahasa Metafora

Gaya bahasa metafora adalah pemakaian kata-kata bukan arti yang sebenarnya, melainkan sebagai lukisan yang berdasarkan persamaan atau perbandingan.

a. "Tidak, lihatlah wajahku, lihat bola mataku"

b. "Kalian tidak akan menemukan walau semili rasa takut itu."

Pada kutipan (a) ungkapan Bola mataku mengandung dua perbandingan yang berbeda yaitu Bola dan mataku. Bola adalah sebuah benda bulat yang dipakai sebagai alat olahraga atau permainan sedangkan mataku adalah 
merupakan indra penglihatan. Ungkapan Bola mataku berarti agar melihat keseriusan dalam diri seseorang lewat tatapan matanya. Pada kutipan (b) hal yang diperbandingkan adalah semili rasa takut itu. Semili berarti ukuran terkecil. Ungkapan semili rasa takut itu berarti tidak mempunyai rasa takut.

c. "Aku telah memperoleh tiket emas yang selama ini aku idamkan."

d. "Mulai mendaki lereng, melewati jalanan setapak, menuju jantung rimba Sumatra."

Pada kutipan (c) ungkapan tiket emas mengandung dua perbandingan yang berbeda yaitu tiket dan emas. Tiket adalah suatu dokumen perjalanan yang dikeluarkan oleh suatu perusahaan yang berisi rute, tanggal, harga daftar penumpang atau karcis masuk. Emas adalah sesuatu ya g tinggi mutunya bernilai dan berharga. Ungkapan tiket emas berarti kesempatan yang sudah lama diharapkan. Pada kutipan (d) hal yang diperbandingkan adalah jantung rimba. Jantung berarti bagian tubuh manusia yang sangat berpengaruh yang terletak di bagian dalam tubuh manusia. Rimba adalah hutan. Ungkapan jantung rimba berarti di hutan dalam hutan yang jauh dengan pemukiman.

6. Gaya Bahasa Hiperbola

Gaya bahasa hiperbola adalah sejenis gaya bahasa yang mengandung pernyataan yang berlebih-lebihan jumlahnya, ukurannya atau sifatnya dengan maksud memberi penekanan pada suatu pernyataan atau situasi untuk memperhebat, meningkatkan kesan dan pengaruhnya.

a. "Sesosok monster mengerikan telah mengambil rasa takutku."

b. "Kami bukan lagi tikus busuk di got."

Pada kutipan (a), gaya bahasa hiperbola terlihat pada penggunaan kata-kata yang berlebihan sifatnya dalam menerangkan hewan buas di hutan. Pada kutipan (b), gaya bahasa hiperbola terlihat pada penggunaan kata-kata yang berlebihan sifatnya dalam menerangkan bahwa terdapat kemajuan dalam kehidupan.

c. "Tatapan matanya yang merah, dengus napasnya yang memburu dan taringnya yang kemilau saat ditimpa cahaya petir telah membelah dadaku, mengeluarkan rasa getar."

Pada kutipan (c), gaya bahasa hiperbola terlihat pada penggunaan kata-kata yang berlebihan sifatnya dalam menerangkan rasa takut yang sangat dalam. 


\section{SIMPULAN}

Berdasarkan hasil analisis terhadap objek kajian dengan mencermati penggunaan gaya bahasa, makna gaya bahasa yang digunakan, dan pengidentifikasian nilai-nilai pendidikan dalam novel Pulang karya Tere Iiye, maka dapat ditarik simpulan sebagai berikut:

1. Gaya bahasa yang terdapat dalam novel Pulang karya Tere Liye meliputi gaya bahasa personifikasi berjumlah $39,62 \%$ pengarang menggunakan gaya bahasa personifikasi untuk memberikan kesan hidup pada adegan-adegan ceritanya sehingga keseluruhan rangkaian ceritanya terkesan lebih menarik. Gaya bahasa metafora berjumlah 33,96\% pengarang menggunakan kiasan tertantang untuk membaca dan memahami maknanya. Gaya bahasa hiperbola berjumlah $26,42 \%$ penggunaan gaya bahasa hiperbola dalam novel Pulang karya Tere Liye membuat rangkaian ceritanya mempunyai nilai rasa yang lebih kuat dan tajam.

2. Nilai pendidikan yang digunakan dalam novel Pulang karya Tere Liye diantaranya adalah nilai pendidikan religi berjumlah $18,75 \%$, melalui nilai religi, pembaca dapat belajar bagaimana cara bersyukur, mengajarkan kita bagaimana cara beriman kepada Tuhan, bersikap jujur tentang permasalahan kecil ataupun besar. Nilai pendidikan moral berjumlah 50\% melalui nilai moral, pengarang mengajarkan pembaca untuk menjadi seorang pemaaf dan menjadi contoh yang baik bagi orang lain, selalu berpikir positif terbadap suatu hal, pantang menyerah, berjiwa besar, dan bekerja keras. Nilai Pendidikan sosial berjumlah $31.25 \%$, melalui nilai pendidikan sosial, pengarang mengajarkan kita selalu menghargai ikatan persaudaraan, mengajarkan kita selalu berbaik sangka terhadap suatu hal agar terhindar dari perbuatan tercela, serta mengajarkan kita untuk setia kawan, menghargai pendapat orang lain, dan memberikan gambaran tentang pemimpin yang baik.

\section{DAFTAR PUSTAKA}

Budianta, M. (2008). Membaca sastra: Pengantar memahami sastra untuk perguruan. Yogyakarta: Indonesia Tera Anggota IKAPI.

Endraswara, S. (2001). Metodologi penelitian sastra. Yogyakarta: Pustaka Widyatama.

Keraf, G. (2010). Diksi dan gaya bahasa. Jakarta: Gramedia.

Liye, T. (2015). Pulang. Jakarta: Republika.

Nurgiyantoro, B. (2002). Kajian prosa dan fiksi. Yogyakarta: Gajahmada Press.

Rahmanto, B. (1998). Metode pengajaran sastra. Yogyakarta. Kanisius.

Sugiyono. (2011). Metodologi penelitian kuantitatif kualitatif dan R\&D. Bandung: Alpabeta. 